\title{
Underwater Welding Techniques
}

\author{
V. Priya, M.Chandra Mohan, J.Dhanasekar
}

\begin{abstract}
Welding demand in toward the ocean and marine applications is extended with the growing in oil and gas practices just as extending in the marine transportation and mechanical applications. In this paper, a succinct delineation of the particular business submerged frameworks will be displayed considering exhibiting natty lumpy portrayal of several forefront welding systems
\end{abstract}

Keywords : Component; formatting; style; styling; insert

\section{INTRODUCTION}

The extending enthusiasm for oil and gas has incited increase the toward the ocean oil and gas practices likewise, to move the examination concerning the significant water. The yearning to fabricate, keep up and fix toward the ocean structures has brought the necessity for submerged welding. Submerged welding is the technique of welding at lifted loads, commonly submerged. Submerged welding can either take put wet in the water itself or dry inside a particularly assembled positive weight separated region what's more, from now on a dry area. It is fantastically insinuated as "hyperbaric welding" when used as a piece of a dry condition, and "submerged welding" when in a wet situation .Principle of Operation The welding circuit must consolidate as a general rule a cutting edge switch worked from the start and charged by the welder and is used for prosperity reasons. At whatever point DC is used with (+ve) furthest point, electrolysis will occur and cause quick disintegrating of any metallic parts in the cathode holder. For wet welding AC isn't used because of electrical prosperity what's more, inconvenience in keeping up a round fragment submerged.

\section{CLASSIFICATION OF UNDERWATER WELDING}

Submerged welding can be partitioned into two principle sorts:

1-Wet Welding

2-Dry Welding

\section{A. Dry welding}

Dry underwater welding:

Revised Manuscript Received on August 22, 2019.

V.Priya, Department of Mechatronics, Bharath Institute of Higher

Education and Research, Chennai, Tamilnadu, India.

Email: priyaygna14@gmail.com

M.Chandra Mohan, Department of Mechatronics, Bharath Institute of

Higher Education and Research, Chennai, Tamilnadu, India.

Email: Jdhanasekar81@ gmail.com

J.Dhanasekar, Department of Mechatronics, Bharath Institute of Higher

Education and Research, Chennai, Tamilnadu, India.

Email: Jdhanasekar81@ gmail.com
Submerged wet welding is fundamentally used at shallow profundities when prerequisite for bigger profundities create submerged dry welding techniques is first choice. Likewise, utilization of submerged dry welding systems offers culmination of full invasion welds with mechanical properties agreeable to welding in common conditions. Moreover, it is possible to perform preheating or post weld heat treatment remembering the ultimate objective to reduce hydrogen substance and improve weld properties. Submerged welding in a dry circumstance is finished in burden fixed around the structure to be welded. The chamber is stacked with a gas (as a rule helium containing 0.5 bar of oxygen) at the general weight[8]. The living space is fixed onto the pipeline and stacked with a breathable blend of helium and oxygen, at or genuinely over the including load at which the welding is to happen. This strategy makes extraordinary weld joints that meet X-bar and code fundamentals. The gas tungsten bend welding methodology is utilized for this system. The zone under the floor of the Habitat is excited about water. All things considered the welding is done in the dry yet at the hydrostatic heap of the ocean water wrapping the Habitat made conceivable by joining the range to be welded with a physical farthest point (weld chamber) that refuses water. The weld chamber is made and uniquely endeavored to suit props and other associate individuals whose inside lines may cross at or close to the zone that is tube welded[3]. The chamber is generally worked of steel, in any case squeezed wood, versatile treated canvas, or whatever other reasonable material can be utilized. Size and structure of the chamber are overseen by estimations and geometry of the zone that must be united and the measure of welders that will work in the chamber in the interim. There are diverse dry submerged welding strategies, it might be rehearsed by[9]:

\section{Dry Habitat Welding:}

This strategy may be would in general as dry regular surroundings welding. As showed up in fig. 2, welders are absolutely in dry condition and weld properties are equal to one welded in average conditions. Regardless, significantly progressively fit-up time is critical to settle nature and set it up for welding 


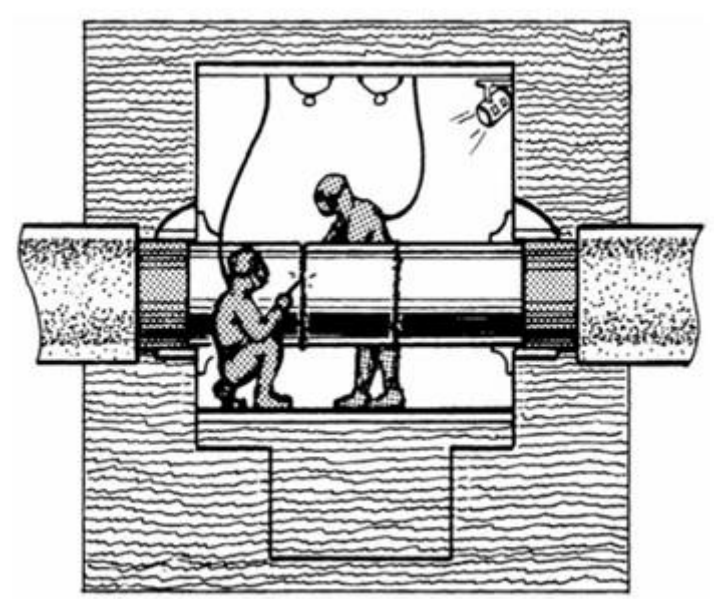

Dry chamber welding:

Welding at incorporating water weight in a fundamental open-base dry chamber that suits the head and shoulders of the welder/jumper in full diving rigging[10]

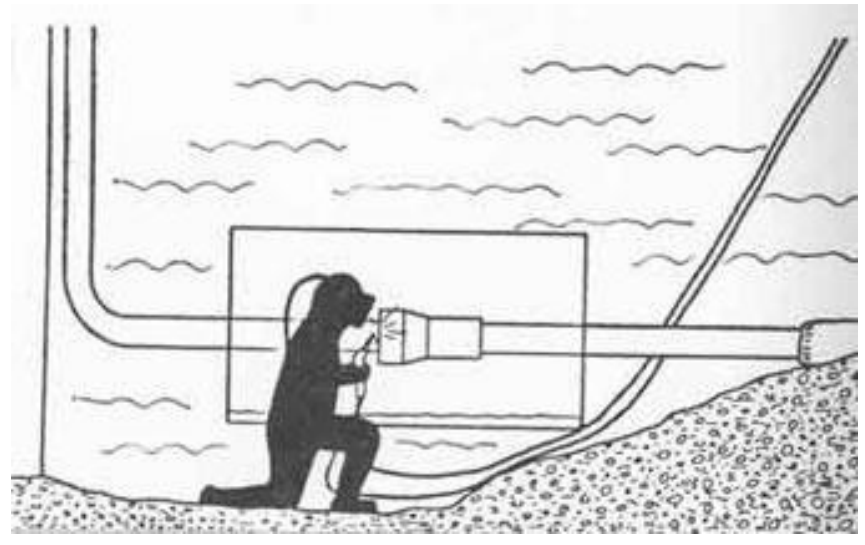

\section{Dry spot welding:}

Welding at encompassing water weight in somewhat direct, gas filled separated territory with the welder/jumper in the water and near the welder/jumper's arm in the isolate region[4].

The good conditions and hindrances of dry Submerged welding strategies are exhibited in

Advantages:

- Better jumper security

- Better quality welds

- No improvement of hydrogen and oxygen pockets

- Takes into thought warm treatment beforehand, at

that point sometime later welding

- Surface watching possible

Disadvantages:

- Requires broad and complex equipment

- Chamber must be fabricated in a sudden manner for different applications

- Cost is high and augmentations with significance

- More essentialness need

\section{B. Wet welding}

Wet welding procedure is finished at surrounding water weight in which, the weld is exhibited to the water. This is finished by a remarkable water-check stick anode, with no physical deterrent among water and welding roundabout

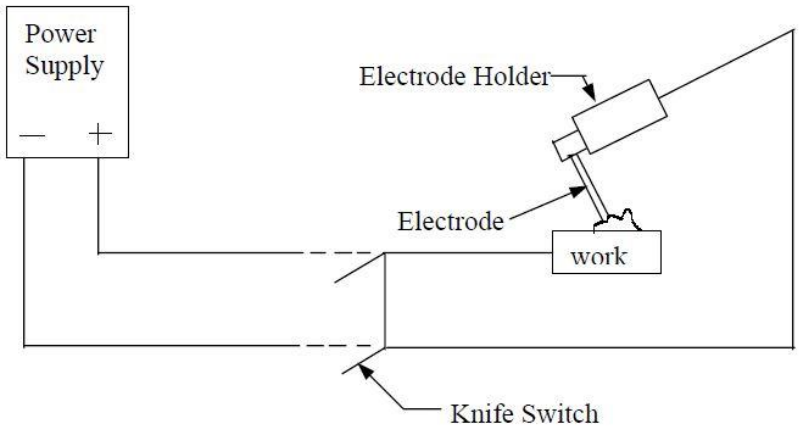

a) Equipment For Underwater Wet Welding:

The submerged wet welding equipment needs to meet all the security angles. On account of the limited time spent submerged. The jumper welder must be given adequate working conditions. Apparatus should be routinely kept up consenting to stipulated controls all together ensure its legitimate working. Essential rigging required for wet submerged welding can be laid out in the accompanying[2].

\section{b) Diving hardware:}

The diving rigging consolidates dry hopping suit, dry suit full-go up against spread, surface inventory umbilical string, air tank from the outset with guideline manometer and blower for filling the air tank.

\section{c) Welding force sources:}

Raised powerful direct of the control source is essential to get an enduring electric roundabout portion in increasingly conspicuous profundities. Welding force source must be adjusted for submerged wet welding, not simply in the matter of good roundabout fragment lead yet furthermore in the part of jumper welder prosperity[5].

\section{d) Safety switch:}

For security reasons, the electrical circuit is fitted with a prosperity switch, which obstructs or sets up the progression of force principal for submerged welding or cutting as jumper request or in case of accident.

\section{e) Communication framework:}

For unfaltering affiliation and coordination of works between the surface and the jumper, two-way phone correspondence system must be associated remembering the ultimate objective to energize the affirmation and association of submerged activities[6].

f) Welding links, and welding and cutting holders:

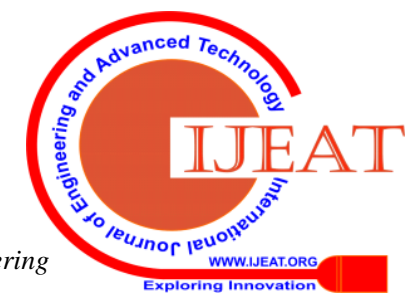


Remarkable connections with unprecedented assurance class must be used for submerged welding and slicing so as to thwart jump forward of electric stream into the water or to the stage structure, which may cause wellbeing issues and issues in welding.

\section{g) Mechanical apparatus framework:}

Mechanical instruments for submerged works may be driven electrically, utilizing pressurized water and pneumatically. Electric drive is kept up a key good ways from by virtue of security issues, and generally water controlled and pneumatic gadgets are used[1]

\section{Advantages:}

- The adaptability and simplicity of wet welding makes this system significantly appealing.

- Quick procedure.

- It is more affordable stood out from dry welding.

- The welder can accomplish portions of toward the ocean structures that couldn't be welded using various procedures.

- No fenced in zones are required and no time is lost structure.

- Minimal gear required for arrangement.

\section{Disadvantages:}

- There is snappy smothering of the weld metal by the enveloping water[7].

- Disregarding the way that smothering forms the unbending nature of the weld, it lessens the malleability and impact nature of the component and extends porosity and hardness.

\section{CONCLUSION}

The weld globule shape and micro structural hardness were examined and connected with the welding parameters of current, voltage and speed. Correlations amongst air and water welds were tried to give a crucial comprehension of the causes behind the regularly watched changes and imperfections in submerged welded joints. In spite of the fact that a number of the outcomes acquired have been anticipated and were normal, the documentation of the fast cooling, solidifying and other warmth stream related data is vital. It was discovered that all water welds delivered a little locale of hard marten site quickly encompassing the weld dot. Hardness esteems in this area approach $600 \mathrm{Hk}(100 \mathrm{~g})$ despite the fact that the degree of this zone is less than $0.5 \mathrm{~mm}$. The HAZ solidifying in submerged welding is not completely out of hand, since higher warmth inputs related with the bigger $3 / 16$ in. electrode did produce e less solidifying. The weld globule state of submerged and air welds was found to be fundamentally the same as at a similar welding current and speed. The closeness of the weld dab shape alongside the practically indistinguishable volt-ampere recordings propose that the essential impact of the water medium is to deliver extremely fast cementing and cooling once the weld puddle has been shaped, furthermore, that the water does not have a significant impact on the entrance or different parts of the weld puddle arrangement.

\section{REFERENCES}

1. Dhanasekar, J., Sengottuvel, P. \& Palanikumar, K. 2019, "Implementation of effective fuel saving methodology for turbines using air drag in vehicles", Materials Today: Proceedings, pp. 421

2. Kumar, S.S., Kumar, K.S.R. \& Kumar, N. 2018, "Experimental evaluation of magnetorheological damper characteristics for vibration analysis", International Journal of Vehicle Structures and Systems, vol. 10, no. 1, pp. 30-34.

3. Dhamodaran, K., Adikesavana, P., Shankar, P.P. \& Gowtham, S. 2018, "Conceptual development of flapping wing for unmanned aerial vehicles: Technical note", International Journal of Vehicle Structures and Systems, vol. 10, no. 1, pp. 43-45.

4. Karthikeyan, S., Raman Balasubramanian, S.R., Ramesh, B., Raghul, S. \& Sathish Kumar, S. 2019, "The automatic solar tracker chronicles", International Journal of Recent Technology and Engineering, vol. 8, no. 1, pp. 312-315.

5. Hema, R., Sundararajan, M. \& Balaji, S. 2019, "Smartphone control robot with automatic firing gun", International Journal of Innovative Technology and Exploring Engineering, vol. 8, no. 9 Special Issue 3, pp. 625-627.

6. Balambica, V., Deepak, V. \& Kumar, S. 2019, "Design and efficiency of an asymmetric gear", International Journal of Mechanical and Production Engineering Research and Development, vol. 9, no. 3, pp. 223-230.

7. Saravana, S., Balaji, S., Arulselvi, S. \& John Paul Praveen, A. 2019, "Reliable power quality monitoring and protection system", International Journal of Innovative Technology and Exploring Engineering, vol. 8, no. 9 Special Issue 3, pp. 644-645.

8. Bycil, V.J. \& Wiselin, M.C.J. 2019, "Modeling and analysis of vibration energy harvesting system using piezo stack", International Journal of Mechanical and Production Engineering Research and Development, vol. 9, no. Special Issue 1, pp. 523-533.

9. Sripada, A., Warrier, A., Kapoor, A., Gaur, H. \& Hemalatha, B. 2018, "Dynamic lateral balance of humanoid robots on unstable surfaces", International Conference on Electrical, Electronics, Communication Computer Technologies and Optimization Techniques, ICEECCOT 2017, pp. 539.

10. Mahalakshmi, V. \& Vijayaragavan, S.P. 2019, "PV based power electronic converters for high voltage DC applications", International Journal of Recent Technology and Engineering, vol. 7, no. 6, pp. 670-674.

\section{AUTHORS PROFILE}

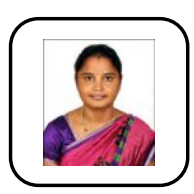

V. Priya Assistant Professor, Department of Mechatronics, Bharath Institute of Higher Education and Research, Chennai, India.

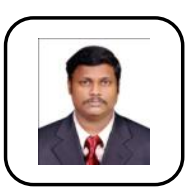

M.Chandra Mohan Assistant Professor, Department of Mechatronics, Bharath Institute of Higher Education and Research, Chennai, India.

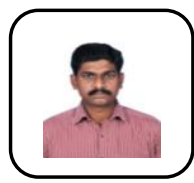

J.Dhanasekar Assistant Professor, Department of Mechatronics, Bharath Institute of Higher Education and Research, Chennai, India. 